\title{
Effects of a Forebrain Embryonic Zinc Finger-Like p.Gly105(12_13) polymorphism on mastitis resistance: an embryo-transfer study
}

\author{
Mayumi Sugimoto ${ }^{1 *}$, Michiko Uchiza ${ }^{2}$ and Masatoshi Kuniyuki ${ }^{3}$ \\ *Correspondence: m0komats@nlbc.go.jp \\ ${ }^{1}$ National Livestock Breeding Center, Nishigo, Fukushima, Japan. \\ ${ }^{2}$ National Livestock Breeding Center, Iwate Station, Morioka, Iwate, Japan. \\ ${ }^{3}$ National Livestock Breeding Center, Miyazaki Station, Kobayashi, Miyazaki, Japan.
}

\begin{abstract}
Background: Mastitis is a common infectious disease of the mammary gland and a major problem in the dairy industry. When cows affect mastitis, the number of somatic cells in their milk increases. It was reported that forebrain embryonic zinc finger-like (FEZL) encoding a stretch of 12 glycines (p.Gly105[12]) instead of 13 glycines (p.Gly105[13]) is associated with a lower somatic cell count, implicating the correlation between FEZL and mastitis resistance.

Findings: To evaluate the impact of FEZL on mastitis incidence, a family with FEZL p.Gly105(12_13) polymorphism was generated via an embryo-transfer procedure. First embryos were recovered from cows inseminated with bulls homozygous for p.Gly105[12] and determined their sex. Based on transferring female embryos into recipient cows, 7 cows carrying the homozygous p.Gly105[12] and 5 cows carrying p.Gly105[12] and p.Gly105[13] were produced. These 12 cows with 15 cows of the same age and carrying the homozygous p.Gly105[13] were raised in the same station. After their deliveries via artificial insemination, milk yield and clinical mastitis were recorded during their first lactation period. Incidence of clinical mastitis was observed among cows carrying p.Gly105[12] significantly less than cows carrying the homozygous p.Gly105[13]. Moreover, affected cows carrying the homozygous p.Gly105[13] produced less milk with higher conductance than affected cows carrying p.Gly105[12], suggesting that cows carrying the homozygous p.Gly105[13] might suffer severer infection than cows carrying p.Gly105[12] because of their impaired immune response.

Conclusions: The impact of FEZL on mastitis resistance was confirmed in a family with FEZL p.Gly105(12_13) polymorphism generated via an embryo-transfer procedure. Selection of cows carrying p.Gly105[12] could be beneficial in the dairy industry by reducing the incidence of mastitis.
\end{abstract}

Keywords: Cattle, mastitis, forebrain embryonic zinc finger-like, somatic cell count

\section{Introduction}

Mastitis is an inflammation of the mammary gland that causes large losses in the dairy industry due to reductions in milk quality/quantity and increased health costs. Linkage analysis of granddaughters derived from Walkway Chief Mark with high and low somatic cell count (SCC) during their first lactation period revealed that high SCC cows have a forebrain embryonic zinc finger-like (FEZL) protein with a longer glycine stretch, i.e., 13 glycines (p.Gly105[13]) instead of 12 (p.Gly105[12]) [1]. FEZL is a transcription factor containing C2H2-type zincfinger domains and a glycine stretch [2]. Treatment of bovine mammary epithelial cells with lipopolysaccharides induces FEZL expression followed by enhanced production of tumor necrosis factor a and interleukin 8 through semaphorin $5 A$ expression [1]. Because p.Gly105[12] promotes higher semaphorin 5A expression than p.Gly105[13], the high SCC might be due to an impaired immune response of cows carrying p.Gly105[13].

A superovulation and an embryo transfer procedures are very common in cattle breeding [3]. These procedures make it possible to determine effects of genetic background in a family raised in the same environment. To estimate the impact of FEZL on mastitis incidence under the same environment, we developed a family with a FEZL p.Gly105(12_13) polymorphism using a superovulation and an embryo transfer procedures.

\section{Findings}

First we genotyped FEZL of Holstein donor cows as described previously [4] and donors carrying p.Gly105[12] received controlled internal Progesterone release (Eazi-breed ${ }^{\mathrm{TM}} \mathrm{CIDR}^{\circledR}$, Livestock Improvement Association of Japan, Tokyo, Japan) from Day 14 (Day $0=$ day of estrus). The cows were administered follicle stimulating hormone (36 IU/cow, Antrin R-10, KawasakiMitaka, Kanagawa, Japan) twice daily in decreasing doses from Day 19 to 22. A Prostaglandin $F_{2 a}$ analogue (Prostavet- $C$, Sankyo Lifetech Co., Ltd., Tokyo, Japan) was administered on Day 22. The cows were inseminated with semen from bulls homozygous for p.Gly105[12] after heat detection. Embryos were recovered by uterine flushing 6 days after artificial insemination. Collected embryos were sexed using loop-mediated isothermal amplification [5]. Female embryos were transferred into recipient cows and 7 cows carrying the homozygous p.Gly105[12] and 5 cows carrying p.Gly105[12] and p.Gly105[13] were produced. 
Sugimoto et al. Molecular Biology and Genetic Engineering 2013,

http://www.hoajonline.com/journals/pdf/2053-5767-1-1.pdf

Table 1. A family with $F E Z L^{*}$ p.Gly105(12_13) polymorphism.

\begin{tabular}{llll}
\hline ID & Birth & Delivery & Genotype of FEZL \\
\hline 1 & $2008 / 12 / 28$ & $2011 / 1 / 30$ & homozygous p.Gly105[12] \\
2 & $2009 / 1 / 21$ & $2011 / 4 / 10$ & homozygous p.Gly105[12] \\
3 & $2009 / 1 / 25$ & $2011 / 5 / 5$ & homozygous p.Gly105[12] \\
4 & $2009 / 4 / 1$ & $2011 / 2 / 3$ & homozygous p.Gly105[12] \\
5 & $2009 / 7 / 17$ & $2011 / 9 / 16$ & homozygous p.Gly105[12] \\
6 & $2009 / 8 / 3$ & $2011 / 8 / 21$ & homozygous p.Gly105[12] \\
7 & $2009 / 8 / 19$ & $2011 / 8 / 5$ & homozygous p.Gly105[12] \\
8 & $2009 / 1 / 18$ & $2011 / 4 / 7$ & p.Gly105[12] \& p.Gly105[13] \\
9 & $2009 / 1 / 18$ & $2011 / 3 / 10$ & p.Gly105[12] \& p.Gly105[13] \\
10 & $2009 / 3 / 3$ & $2011 / 2 / 12$ & p.Gly105[12] \& p.Gly105[13] \\
11 & $2009 / 7 / 25$ & $2011 / 9 / 19$ & p.Gly105[12] \& p.Gly105[13] \\
12 & $2009 / 10 / 26$ & $2011 / 10 / 3$ & p.Gly105[12] \& p.Gly105[13] \\
13 & $2008 / 12 / 25$ & $2011 / 2 / 5$ & homozygous p.Gly105[13] \\
14 & $2009 / 1 / 14$ & $2011 / 3 / 20$ & homozygous p.Gly105[13] \\
15 & $2009 / 3 / 2$ & $2011 / 1 / 31$ & homozygous p.Gly105[13] \\
16 & $2009 / 3 / 3$ & $2011 / 4 / 10$ & homozygous p.Gly105[13] \\
17 & $2009 / 3 / 24$ & $2011 / 3 / 9$ & homozygous p.Gly105[13] \\
18 & $2009 / 3 / 29$ & $2011 / 3 / 31$ & homozygous p.Gly105[13] \\
19 & $2009 / 4 / 8$ & $2011 / 2 / 12$ & homozygous p.Gly105[13] \\
20 & $2009 / 4 / 12$ & $2011 / 3 / 27$ & homozygous p.Gly105[13] \\
21 & $2009 / 5 / 27$ & $2011 / 10 / 6$ & homozygous p.Gly105[13] \\
22 & $2009 / 8 / 12$ & $2011 / 8 / 16$ & homozygous p.Gly105[13] \\
23 & $2009 / 8 / 12$ & $2011 / 9 / 5$ & homozygous p.Gly105[13] \\
24 & $2009 / 8 / 24$ & $2011 / 8 / 3$ & homozygous p.Gly105[13] \\
25 & $2009 / 8 / 27$ & $2011 / 10 / 8$ & homozygous p.Gly105[13] \\
26 & $2009 / 9 / 15$ & $2011 / 9 / 7$ & homozygous p.Gly105[13] \\
27 & $2009 / 10 / 15$ & $2011 / 9 / 3$ & homozygous p.Gly105[13] \\
\hline & &
\end{tabular}

${ }^{*}$ FEZL: Forebrain Embryonic Zinc Finger-Like

Next we raised these 12 cows with 15 cows of the same age and carrying the homozygous p.Gly105[13] in the same station (Table 1). When these 27 cows became older than 13 months old and went into heat, they received artificial insemination. After their deliveries, we recorded milk yield and conductance everyday using robotic milking system (Astrounaut, Lely, Maassluis, The Netherlands) for 305 days during their first lactation period. Milk yield decreased and electrical conductivity of milk increased when cows were infected $[6,7]$. We also recorded SCC once a week because elevated SCC was caused by mammary infection [8]. When cows showed low milk yield ( $>30 \%$ change), high conductance $(>8$ $\mathrm{mS} / \mathrm{cm})$, or high SCC $(>300000 / \mathrm{mL})$, we conducted California mastitis test [9] to check whether they affected mastitis. Affected cows were treated with antibiotics until showing negative results in California mastitis test.

Incidence of clinical mastitis was observed among cows carrying the homozygous p.Gly105[13] significantly more
Table 2. The incidence of clinical mastitis of cows with heterozygous or homozygous p.Gly105[12] and cows with homozygous p.Gly105[13].

\begin{tabular}{|c|c|}
\hline $\begin{array}{l}\text { Homozygous p.Gly105[12] or } \\
\text { heterozygous p.Gly105[12] }\end{array}$ & Homozygous p.Gly105[13] \\
\hline 0 & 3 \\
\hline 2 & 0 \\
\hline 1 & 2 \\
\hline 1 & 0 \\
\hline 6 & 2 \\
\hline 0 & 1 \\
\hline 1 & 1 \\
\hline 0 & 2 \\
\hline 1 & 1 \\
\hline 1 & 3 \\
\hline 2 & 2 \\
\hline 5 & 10 \\
\hline-- & 3 \\
\hline-- & 1 \\
\hline-- & 0 \\
\hline \multicolumn{2}{|c|}{$\mathrm{p}^{*}=0.023$} \\
\hline
\end{tabular}

${ }^{*} \mathrm{p}$ value calculated by Wilcoxon's rank sum test.

Table 3. The averages \pm SEM of milk yield and conductance of cows with heterozygous or homozygous p.Gly105[12] compared to cows with homozygous p.Gly105[13] during mastitis period.

\begin{tabular}{lccc}
\hline Genotype of FEZL & $\begin{array}{l}\text { Homozygous p.Gly105[12] } \\
\text { or heterozygous p.Gly105[12] }\end{array}$ & $\begin{array}{l}\text { Homozygous } \\
\text { p.Gly105[13] }\end{array}$ & p value $^{*}$ \\
\hline Milk $[\mathrm{kg} / \mathrm{day}]$ & $35.59 \pm 0.46$ & $32.37 \pm 0.45$ & $8.4 \mathrm{E}-07$ \\
Conductance $[\mathrm{mS} / \mathrm{cm}]$ & $6.80 \pm 0.02$ & $6.98 \pm 0.02$ & $3.5 \mathrm{E}-14$ \\
\hline
\end{tabular}

${ }^{*} \mathrm{p}$ value calculated by Student's t-test.

than cows carrying p.Gly105[12] based on Wilcoxon's rank sum test (Table 2). The average \pm SEM of mastitis incidence in cows carrying the homozygous p.Gly105[13] was $2.1 \pm 0.7$, whereas that in cows carrying p.Gly $105[12]$ was $1.7 \pm 0.6$. We used Wilcoxon's rank sum test because the mastitis incidence did not show normal distribution [10]. Moreover, affected cows carrying the homozygous p.Gly105[13] produced less milk with higher conductance than affected cows carrying p.Gly105[12] (Table 3), indicating that cows carrying the homozygous p.Gly105[13] might be more serious conditions when affected mastitis than cows carrying p.Gly105[12]. These observations suggest that FEZL has an effect on mastitis resistance.

Here we showed effects of the FEZL p.Gly105(12_13) polymorphism on mastitis resistance in a family generating via a superovulation and an embryo transfer procedures. A recent survey of the FEZL p.Gly105(12_13) polymorphism in sires in Japan also demonstrated that the p.Gly105[12] allele decreases the incidence of mastitis [4]. Considering the high health costs associated with mastitis, it might be beneficial to select cows based on their FEZL type. 


\section{Competing interests}

The authors declare that they have no competing interests.

\section{Authors' contributions}

MS participated in the design of study, performed the statistical analysis, and drafted the manuscript. MU participated in the design of the study and performed the embryo transfer. MK participated in the design of study, performed the embryo transfer, and raised the family. Final manuscript was read and approved by all the authors.

\section{Acknowledgement}

The authors thank M. Masuda and all staff in Iwate and Miyazaki stations for assistance.

\section{Publication history}

Editors: Pramod K Rout, Central Institute for Research on Goats (CIRG), India.

Othman El Mahdy Sayed Othman, National Research centre, Egypt. Received: 11-Jul-2013 Revised: 22-Jul-2013

Accepted: 07-Aug-2013 Published: 14-Aug-2013

\section{References}

1. Sugimoto M, Fujikawa A, Womack JE and Sugimoto Y. Evidence that bovine forebrain embryonic zinc finger-like gene influences immune response associated with mastitis resistance. Proc Natl Acad Sci U S A. 2006; 103:6454-9. | Article | PubMed Abstract | PubMed Full Text

2. Matsuo-Takasaki M, Lim JH, Beanan MJ, Sato SM and Sargent TD. Cloning and expression of a novel zinc finger gene, Fez, transcribed in the forebrain of Xenopus and mouse embryos. Mech Dev. 2000; 93:201-4. I Article I PubMed

3. Hasler JF. The current status and future of commercial embryo transfer in cattle. Anim Reprod Sci. 2003; 79:245-64. I Article I PubMed

4. Sugimoto M, Itoh T, Gotoh $Y$, Kawahara T, Moriya H, Uchimura $Y$ and Sugimoto Y. Enhanced clinical mastitis resistance in Holsteins with a FEZL p.Gly105(12_13) polymorphism. J Dairy Sci. 2011; 94:2103-7. | Article I PubMed

5. Hirayama H, Kageyama S, Moriyasu S, Sawai K, Onoe S, Takahashi Y, Katagiri S, Toen K, Watanabe K, Notomi T, Yamashina H, Matsuzaki S and Minamihashi A. Rapid sexing of bovine preimplantation embryos using loop-mediated isothermal amplification. Theriogenology. 2004; 62:88796. | Article | PubMed

6. Norberg E, Hogeveen H, Korsgaard IR, Friggens NC, Sloth $\mathrm{KH}$ and Løvendahl P. Electrical conductivity of milk: ability to predict mastitis status. J Dairy Sci. 2004; 87:1099-107. | Article | PubMed

7. Buret AG. Immuno-modulation and anti-inflammatory benefits of antibiotics: the example of tilmicosin. Can J Vet Res. 2010; 74:1-10. | PubMed Abstract | PubMed Full Text

8. Goldammer T, Zerbe H, Molenaar A, Schuberth HJ, Brunner RM, Kata $\mathrm{SR}$ and Seyfert HM. Mastitis increases mammary mRNA abundance of beta-defensin 5, toll-like-receptor 2 (TLR2), and TLR4 but not TLR9 in cattle. Clin Diagn Lab Immunol. 2004; 11:174-85. | Article | PubMed Abstract | PubMed Full Text

9. Sargeant JM, Leslie KE, Shirley JE, Pulkrabek BJ and Lim GH. Sensitivity and specificity of somatic cell count and California Mastitis Test for identifying intramammary infection in early lactation. J Dairy Sci. 2001; 84:2018-24. | Article | PubMed

10. Adams DA. Statistics and reports: collecting, interpreting, and presenting numerical data. Lab Math 2003, 193-234.
Citation: Sugimoto M, Uchiza M and Kuniyuki M. Effects of a Forebrain Embryonic Zinc Finger-Like p.Gly105(12_13) polymorphism on mastitis resistance: an embryo-transfer study. Mol Biol Genet Eng. 2013; 1:1. http://dx.doi.org/10.7243/2053-5767-1-1 